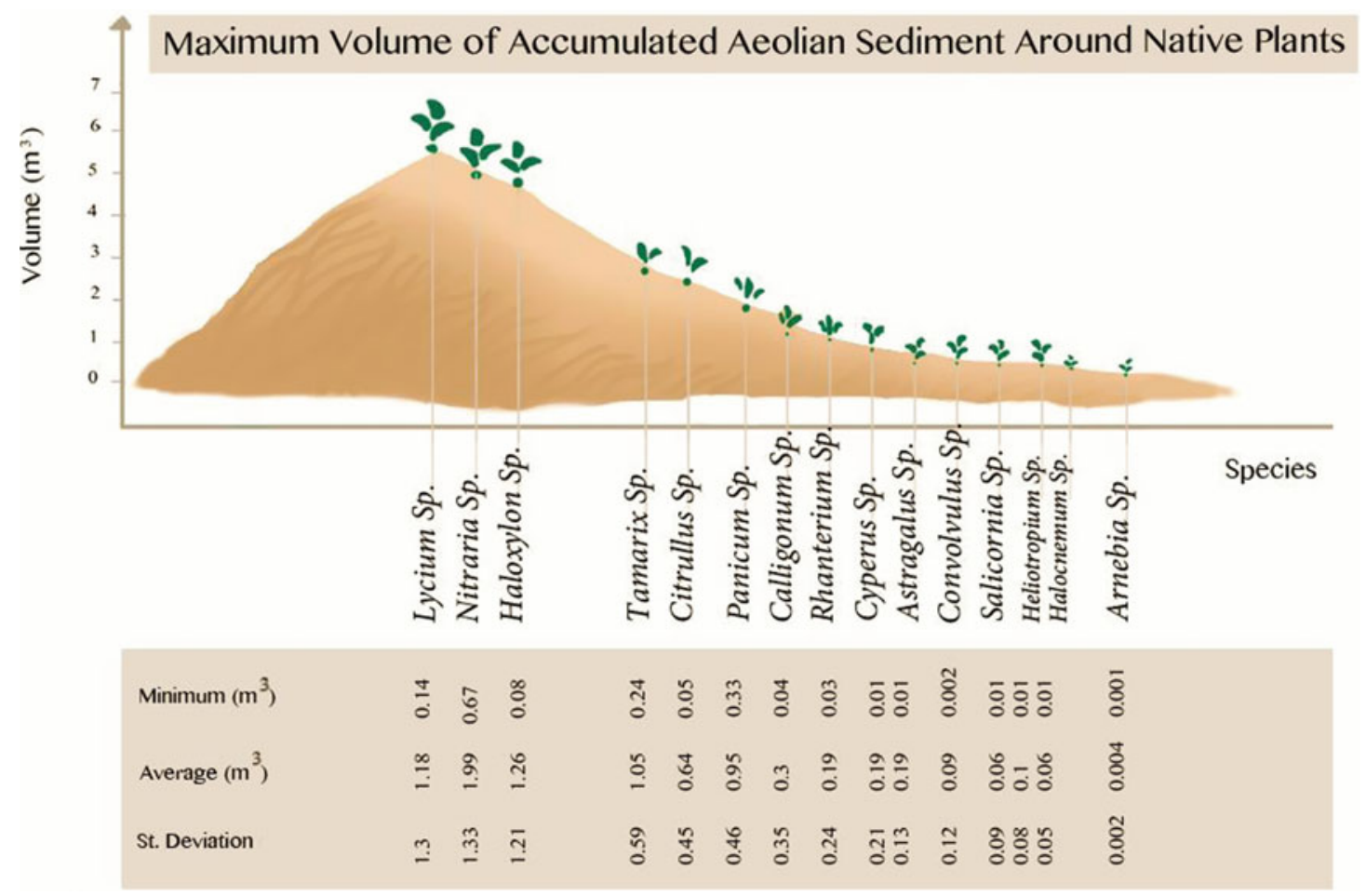




\title{
Other Properties (BET Surface Area, Conductivity, Organic Matter, and pH)
}

\author{
Modi Ahmed and Khaliq Beg
}

\section{Abstract}

- Brunauer, Emmett, and Teller (BET) test were applied to dust samples in which samples (BET) surface area is highly related to the roundness of dust particles. The higher angularity and low roundness of the dust particles show a higher (BET) surface area. The roundness is also related to the particle size distribution and mineralogical composition.

- The electrical conductivity test relates very well with the chemical and physical properties of dust samples in the transmission of an electrical current.

- The organic matter content was measured using the ignition method and the $\mathrm{pH}$ of the samples was recorded.

- Maps of the distribution of high and low BET concentrations, electrical conductivity EC, organic matter content, $\mathrm{pH}$.

\section{Methods}

\section{BET Surface Area}

The BET surface area is a specific measurement of the area of the dust particle surface. BET surface area resolute BET through gas physical adsorption of the dust particle surface by calculating the mass of adsorbed gas corresponding to a monomolecular layer on the particle surface. The gas physical adsorption results from weak van der Waals forces between the adsorbent surface area of the tested dust particles and the adsorbed nitrogen gaseous molecules. The determination is frequently carried out at the temperature of liquid nitrogen. The mass of gas adsorbed can be determined by either a volumetric or continuous flow process. The measurement of the BET surface area for dust particles was made using a COULTER-SA 3100 (Fig 8.1).
M. Ahmed $(\bowtie) \cdot$ K. Beg

Crisis Descision Supports Program (CDS), Environment \& Life

Sciences Research Center (ELSRC), Kuwait Institute for Scientific

Research (KISR), P.O. Box: 24885 Safat, 13109, Kuwait

e-mail: mmahmed@kisr.edu.kw

K. Beg

e-mail: krbeg@kisr.edu.kw 


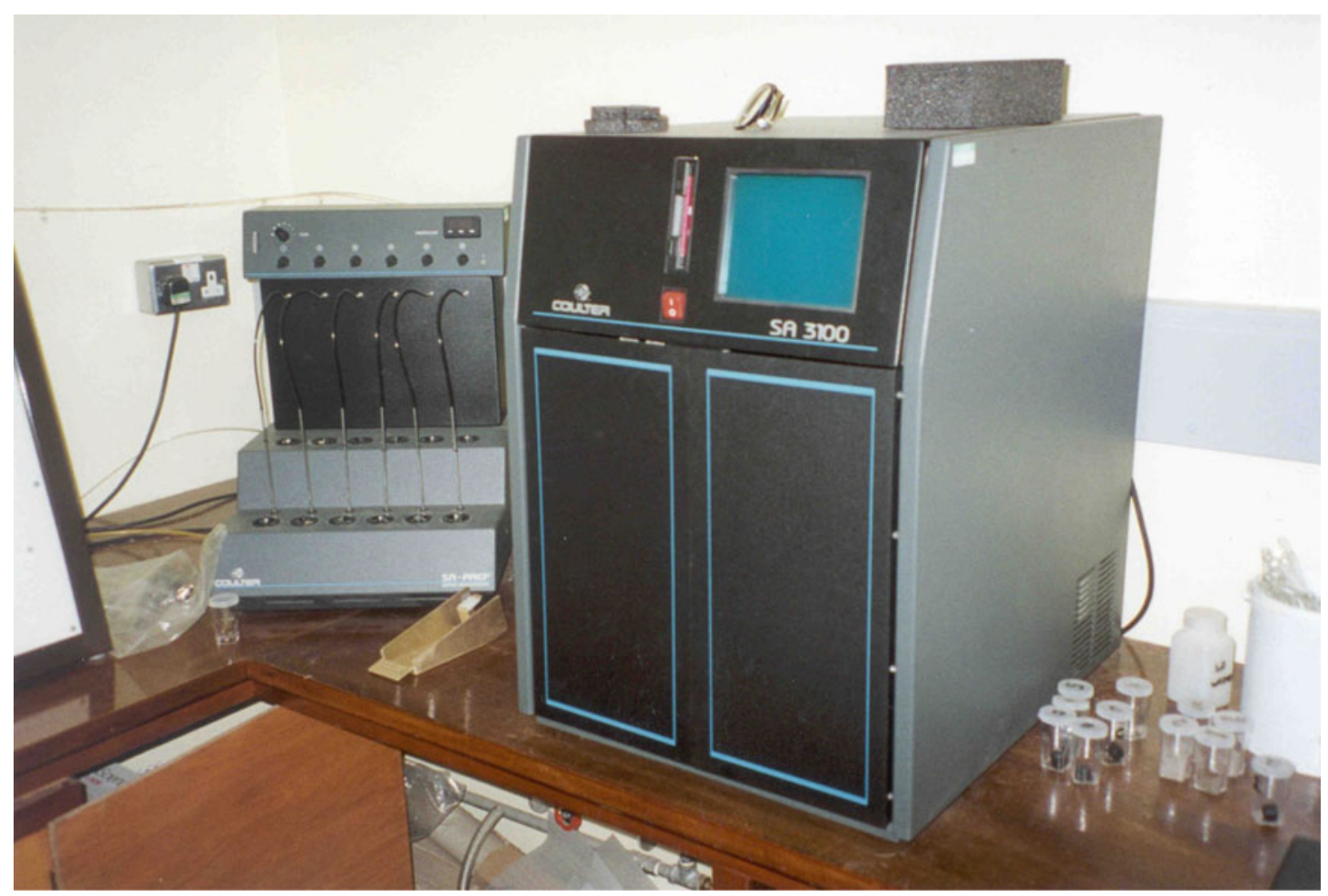

Fig. 8.1 COULTER-3100 for measuring the BET surface area for dust particles

\section{Electrical Conductivity}

Electrical conductivity is a measurement that relates very well with the chemical and physical properties of dust samples. Electrical conductivity is the capability of a sample to transmit an electrical current, and it is normally expressed in units of deciSiemens per meter $(\mathrm{dS} / \mathrm{m})$. The electrical conductivity measurements can be expressed in milliSiemens per meter $(\mathrm{mS} / \mathrm{m})$ also, which is 100 times less than deciSiemens per meter.

\section{pH}

The dust samples were mixed in $125 \mathrm{ml}$ of distilled water. The mixture was shaken in an electrical shaker for one hour and then left to settle for one hour. The resulting suspension was used for $\mathrm{pH}$ determination (Fig 8.2). 

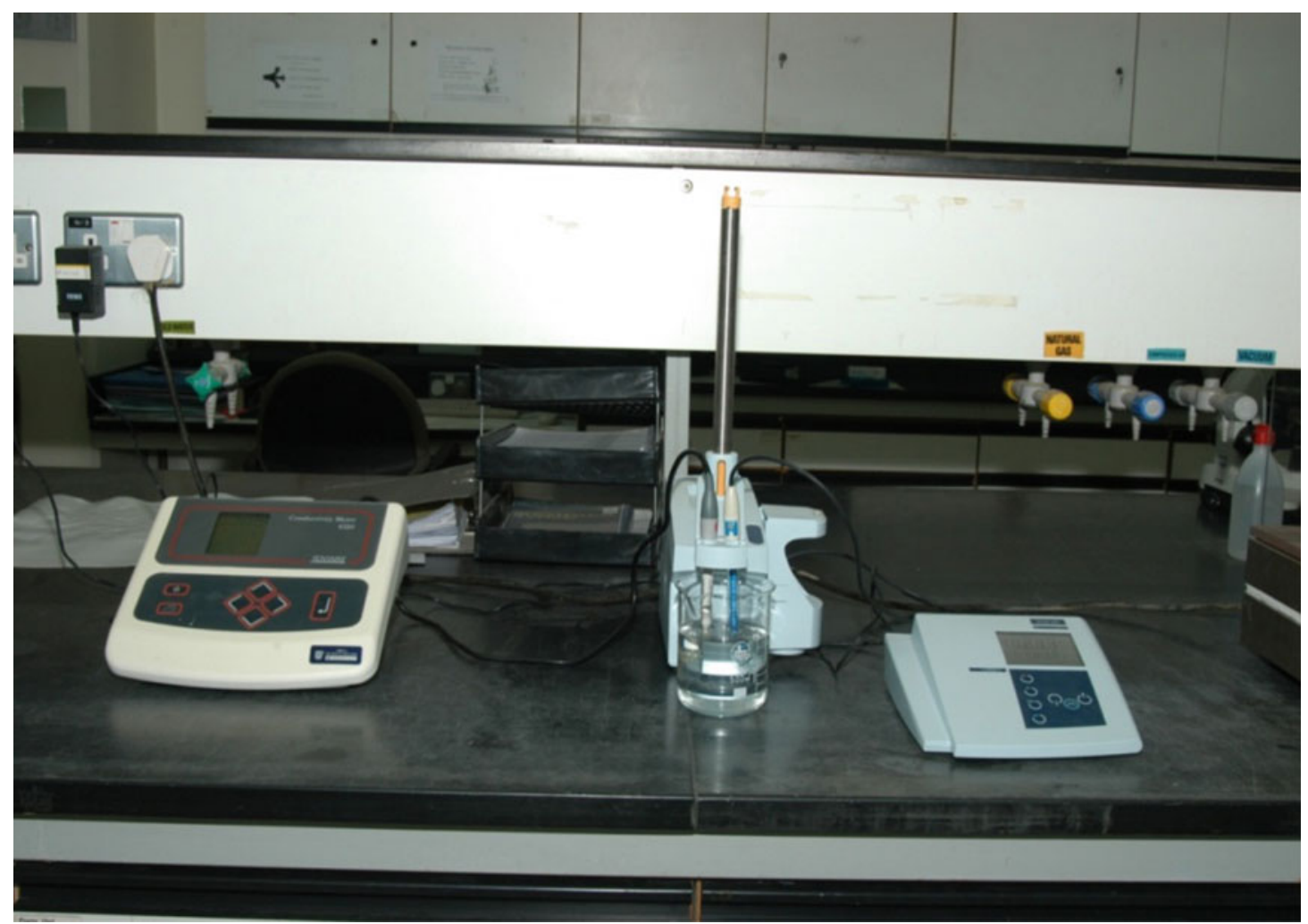

Fig. 8.2 Conductivity and $\mathrm{pH}$ meter used for dust samples

\section{Organic Matter}

The organic matter was measured using the ignition method, in which the dust sample was weighed, dried in an oven at $60 \mathrm{C}$ for $24 \mathrm{~h}$, weighed again, and then washed in a muffle furnace at $400{ }^{\circ} \mathrm{C}$ for four hours. The organic matter was calculated by using the difference of the initial weight and the final weight multiplied by 100/58. Organic matter $\%=$ organic carbon $\% \times 11 / 58$. 


\section{BET-Surface Area}

The BET surface area is highly related to the roundness of dust particles. The higher angularity and low roundness of the dust particles reveal a higher BET surface area. The roundness is also related to the particle size distribution and mineralogical composition. Dust samples with smaller size fractions and lower quartz percentages have higher values of BET surface area. The dust samples in the northeastern part of Kuwait and near the coastal area have higher BET surface areas, with values of more than $12 \mathrm{~m}^{2} / \mathrm{g}$. This result is attributed to geographical reasons, as those areas with high BET surface area are close to the Mesopotamian Floodplain and Al-Ahwar areas in Iraq, as dust coming from those areas is low in quartz and high in carbonates, feldspars, clay, and heavy minerals. Furthermore, the dust samples in summertime are expected to have a low BET surface area compared with winter (Fig. 8.3).

\begin{tabular}{l|l}
\hline $\begin{array}{l}\text { Areas with high BET } \\
\text { concentration }\end{array}$ & $\begin{array}{l}\text { Areas with low BET } \\
\text { concentration }\end{array}$ \\
\hline Abdulli & Warba Island \\
Subiyah & Khur Fawaris \\
Jal Al Zur & Shegaya \\
Khiran & Dibdibah \\
Sulaybiyah & Mutla \\
\hline
\end{tabular}

\section{Conductivity}

Electrical conductivity (EC) is a measurement of the dissolved material associated with or attached to dust samples, which relates to the ability of the material to conduct an electrical current. More salt or evaporated minerals, such as halite, gypsum, and anhydrite, cause higher values of EC. High conductivity is present on Bubiyan Island and the southern sector of Kuwait, as most sabkhas are present. Sabkhas contain salt minerals that cause an increase in conductivity. The areas extending from Jirashan in the northwest, near the Iraqi border, to northern Kuwait Bay displayed minimum values of conductivity readings (Fig. 8.4).

\begin{tabular}{l|l}
\hline $\begin{array}{l}\text { Areas with high conductivity } \\
\text { concentration }\end{array}$ & $\begin{array}{l}\text { Areas with low conductivity } \\
\text { concentration }\end{array}$ \\
\hline $\begin{array}{l}\text { Bubiyan Island } \\
\text { Failaka Island }\end{array}$ & Warba Island \\
Kabd & Liyah \\
Um Qudayr & Shegaya \\
Khur Fawaris & Jal Al Zur \\
\hline
\end{tabular}
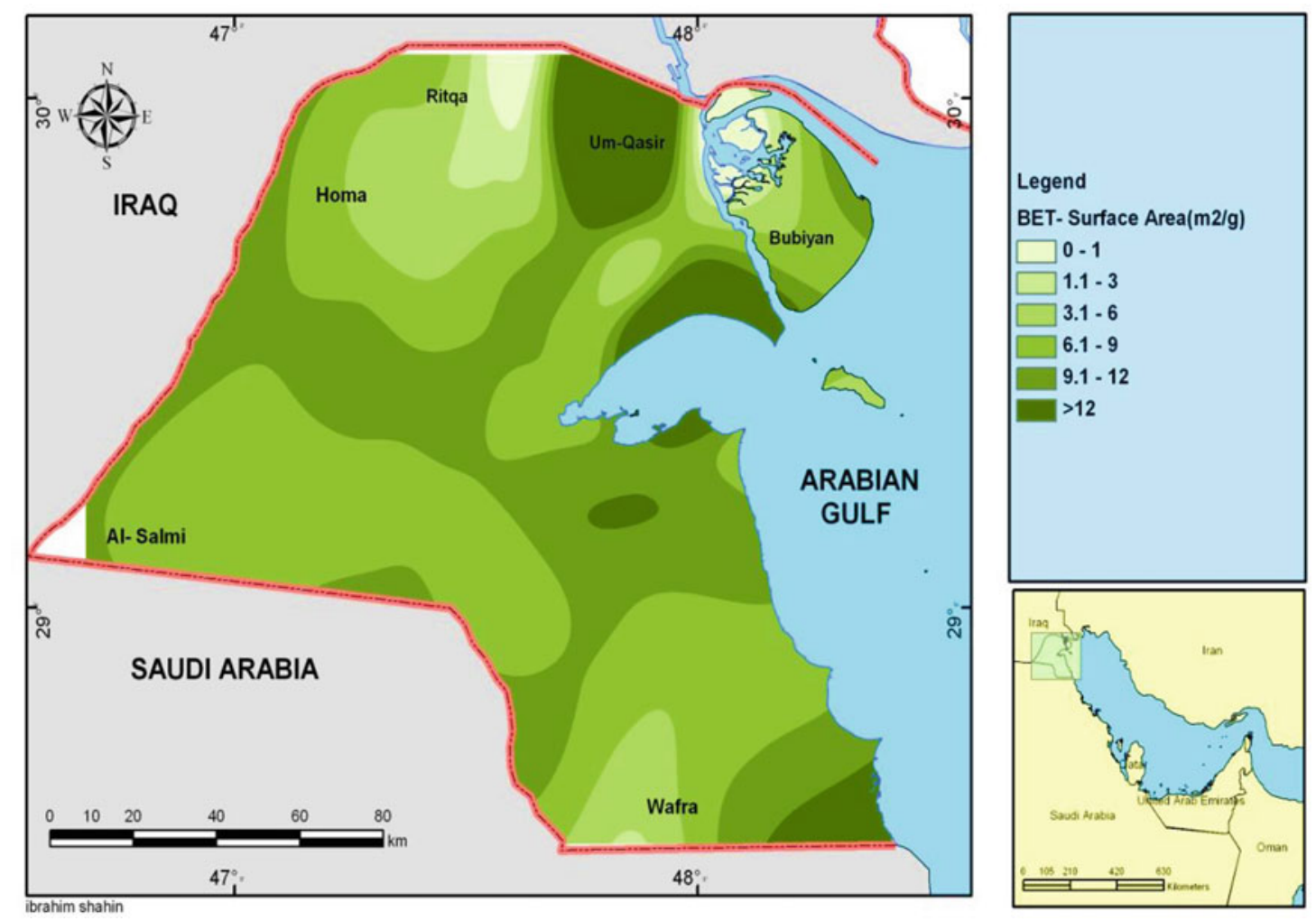

Fig. 8.3 Surface area distribution of dust in Kuwait 


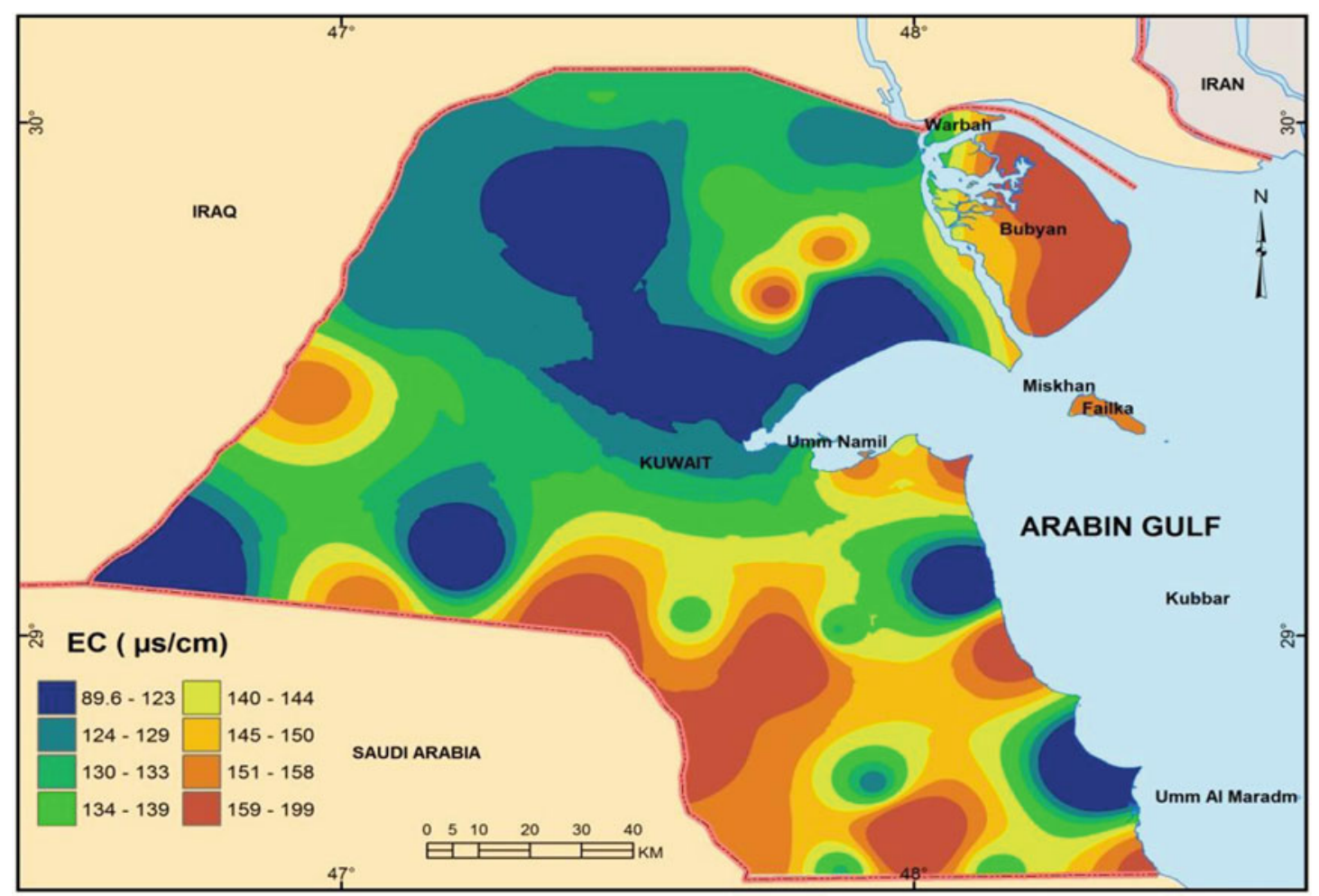

Fig. 8.4 Conductivity area distribution for dust in Kuwait

\section{Organic Matter}

Organic matter is measured with reference to the total weight percentage for the dust samples. The values were restricted, from $1.38 \%$ to about $9 \%$. The highest percentages of dust values containing organic matter within the dust samples were in the northeastern part of Kuwait and around farms. The presence of high organic matter percentages in dust samples collected in the northeastern parts of Kuwait is attributed to the type of dust, which mostly originates from the Mesopotamian Floodplain. Lower percentages were in the west and northwest of Kuwait. Compared with other dust in the world, deposited dust in Kuwait can be classified as being rich in organic matter. Therefore, dust plays a major role in maintaining the ecological system in the region, and the organic matter in dust is essential, mainly to the marine environment (Fig. 8.5).

\begin{tabular}{l|l}
\hline $\begin{array}{l}\text { Areas with high organic matter } \\
\text { concentration }\end{array}$ & $\begin{array}{l}\text { Areas with low organic matter } \\
\text { concentration }\end{array}$ \\
\hline Bubiyan Island & Ubayriq \\
Dibdibah & Khur Fawaris \\
Um Niqa & Salmi \\
Failaka Island & Shegaya \\
Wafra Farms & Burqan \\
\hline
\end{tabular}




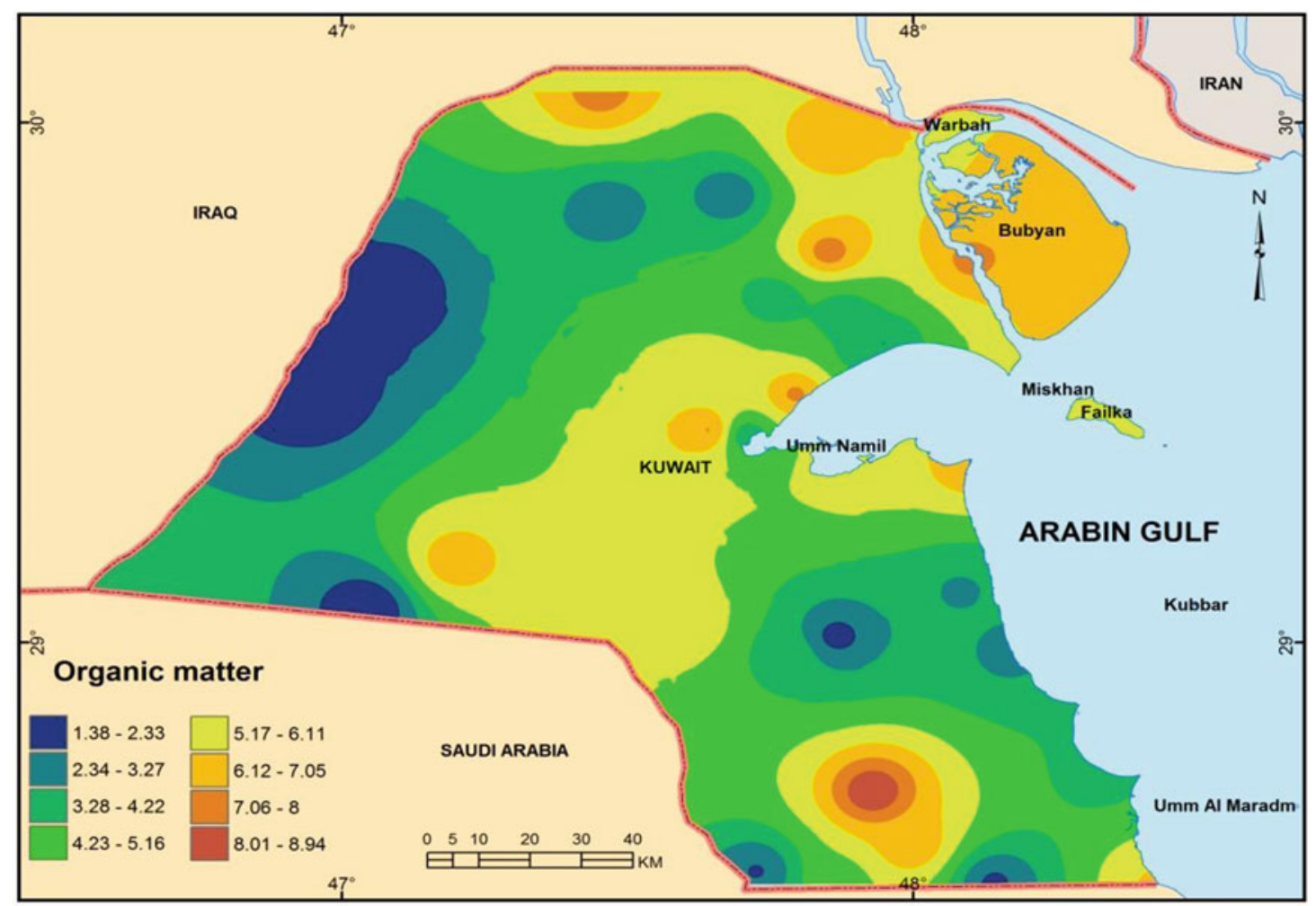

Fig. 8.5 Organic matter area distribution for dust in Kuwait

\section{pH}

The dust is more basic than acidic. The variation in $\mathrm{pH}$ values is from 7.4 to 8.1 . The highest values are present in three areas, namely Huwamilyah, Um Al-Qawatti, and Atraf, while the lowest are present in Jirashan, Shuaiba, Khur Fawaris, and Um Niqa.

These results might indicate that dust occurring in the northwest, from the Western Desert of Iraq, is more basic than the dust coming from other directions, mainly the
Mesopotamian Foodplain, Iran, and Saudi sides. The $\mathrm{pH}$ level might be related to humidity, as Saudi source areas of dust are more humid (Fig. 8.6).

\begin{tabular}{l|l}
\hline $\begin{array}{l}\text { Areas with high Ph } \\
\text { concentration }\end{array}$ & $\begin{array}{l}\text { Areas with low } \mathrm{Ph} \\
\text { concentration }\end{array}$ \\
\hline Bubiyan Island & Shuaiba \\
Huwaymilyah & Khur Fawaris \\
Khiran & Ratqah \\
Atraf & Dibdibah \\
Um Al-Qawatti & Um Niqa \\
\hline
\end{tabular}




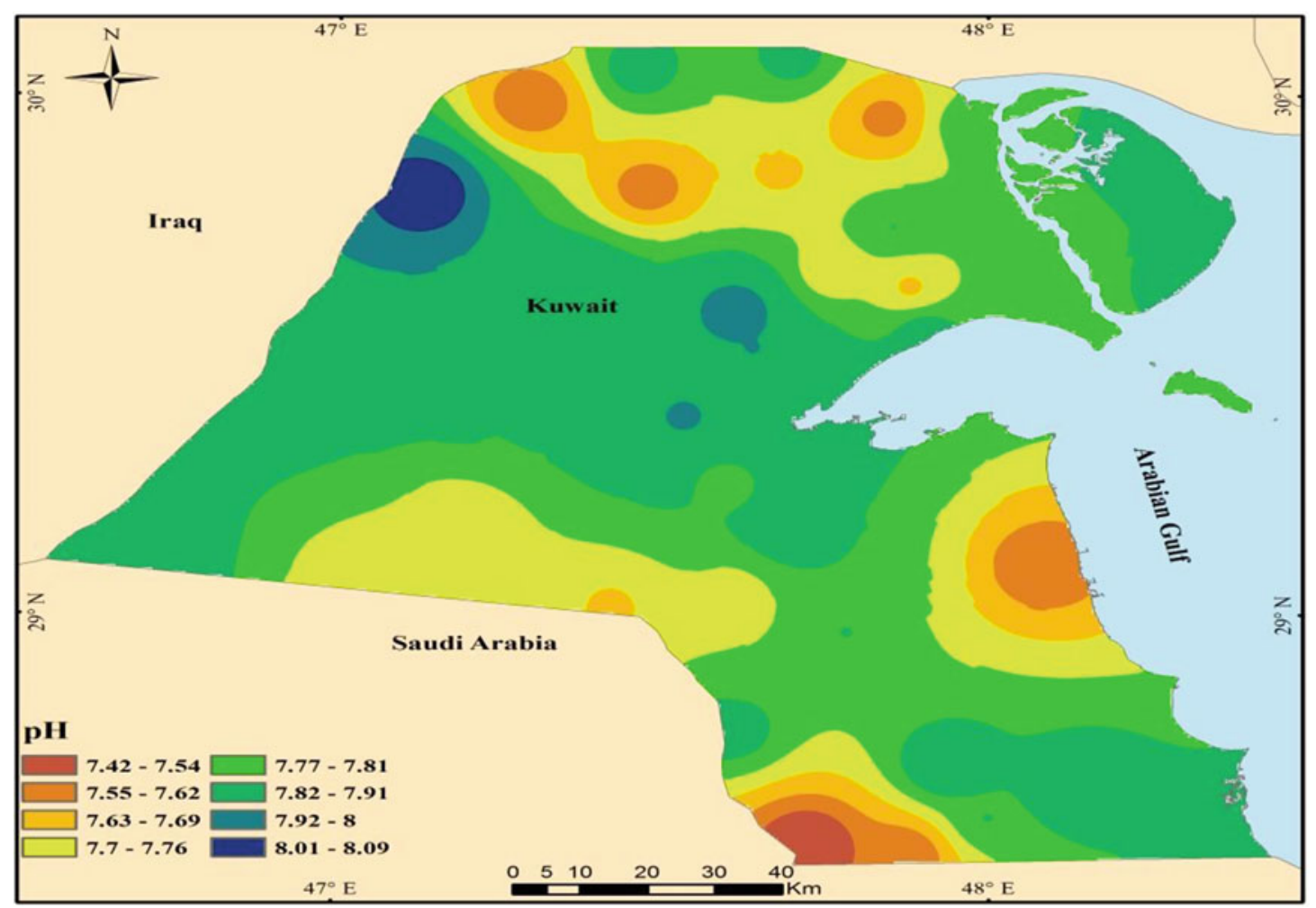

Fig. 8.6 Ph distribution for dust in Kuwait

Open Access This chapter is licensed under the terms of the Creative Commons Attribution 4.0 International License (http:// creativecommons.org/licenses/by/4.0/), which permits use, sharing, adaptation, distribution and reproduction in any medium or format, as long as you give appropriate credit to the original author(s) and the source, provide a link to the Creative Commons licence and indicate if changes were made.
The images or other third party material in this chapter are included in the chapter's Creative Commons licence, unless indicated otherwise in a credit line to the material. If material is not included in the chapter's Creative Commons licence and your intended use is not permitted by statutory regulation or exceeds the permitted use, you will need to obtain permission directly from the copyright holder. 